\title{
The Hendrix chord: blues, flexible pitch relationships, and self-standing harmony ${ }^{1}$
}

\author{
ROB VAN DER BLIEK
}

Sound and Moving Image Library, York University, 4700 Keele St, Toronto, Ontario M3J 1P3, Canada E-mail: bliek@yorku.ca

URL: http://www.yorku.ca/bliek

\begin{abstract}
Jimi Hendrix was often characterised by his exotic appearance and extravagant performance, but underneath these trappings was an extraordinary guitarist who managed to transform some of the key elements of blues and rhythm-and-blues traditions. An important feature of Hendrix's music is his characteristic use of the seventh chord with a sharp ninth, or the augmented ninth chord, now often referred to as the 'Hendrix chord'. This paper examines some ways in which Hendrix used this chord by surveying and drawing comparisons between various instances. It is not necessarily the fully voiced version of the chord that Hendrix used, but interval combinations drawn from or related to it, with particular timbres and articulations. Together these define what might be called a 'sharp ninth sound'. Through register placement, timbre, articulation, and chordal function, it is intimately tied to the blues idiom, adding a blues tonal element. This is one aspect of Hendrix's music, then, that shows his deep roots in the blues.
\end{abstract}

Jimi Hendrix (1942-1970) revolutionised the playing of the electric guitar during the four years (1967-1970) of his career as a rock superstar, expanding its tonal and timbral possibilities through an innovative melding of blues, rhythm-and-blues, and rock with various timbre-shaping techniques and devices. He was often characterised in terms of his exotic appearance, stage mannerisms, the high volume at which he played, and the myriad of sound effects he experimented with, but underneath these trappings was an extraordinary guitarist who managed to transform some of the key elements of the blues and rhythm-and-blues traditions into something that seemed light-years from what everybody else was doing.

An important and widely recognised feature of Hendrix's music is his characteristic use of the seventh chord with a sharp ninth, or the augmented ninth chord. ${ }^{2}$ It is perhaps most familiar to us through 'Purple Haze', an early hit record with a memorable riff and inspired lyrics that became a signature piece for him, and judging from most accounts it was this particular instance that led to the appellation, 'Hendrix chord'. ${ }^{3}$ The most common voicing for this chord on the guitar, as played in E, is $e-g \sharp-d-g$, and indeed, this voicing is used as the first chord in 'Purple Haze', in this case functioning as tonic. Hendrix used the chord extensively, or at least characteristic interval combinations drawn from it, in about one third of his studio recordings and numerous concert performances, establishing it as an essential component in the identity of his sound. 
This paper will examine some of the different ways in which Hendrix used the seventh chord with a sharp ninth. ${ }^{4}$ After surveying and drawing comparisons between the various instances it will become apparent that it is not necessarily the fully voiced version of the chord that Hendrix used, but interval combinations drawn from or related to it, with particular timbres and articulations, thereby defining what might more usefully be called a 'sharp ninth sound'. 5 Through register placement, timbre, articulation, and chordal function, the sound is intimately tied to the blues idiom, and as such it can be said to add a blues tonal element. Hendrix's music is deeply rooted in the blues, and this is one aspect of his music that clearly exposes these roots.

\section{Blues performance practice and the sharp ninth sound}

Melodic activity in the blues idiom is characterised by a pentatonicism that includes several mobile or flexibly intonated pitches (usually referred to as blue notes) with stylistically consistent note bending or inflections around the third, seventh, fifth, and to a lesser extent sixth and second degrees, combined with specific types of articulation and phrasing. ${ }^{6}$ As Weisethaunet puts it, there is 'a constant interplay between pitches, between major and minor thirds; between flattened fifths, fourths and fifths; thirds and flattened sevenths; bent seconds; sixths ... phrases rarely seem to be made out of "one scale", rather they will be based on interplay, bends, slurs, slides, etc. between notes and against the layers of bass lines, guitar riffs and contrasting chords' (Weisethaunet 2001, p. 108). Although the standard twelve-bar blues form with its associated harmonic scheme and phrase structure is often perceived as being the key element in characterising or at least recognising a piece as being part of the blues idiom, it can be a misleading characterisation since it is entirely possible to use the form without it sounding as though it belongs to the blues idiom. Indeed, playing the twelve-bar form without the characteristic melodic activity and timbral distinctiveness that is associated with the blues may give the impression that the performance is actually less blues-like than if these characteristic attributes of blues idiom were to be employed without the twelve-bar form. ${ }^{7}$

Of interest to this study is the manner in which the third is used over both tonic and non-tonic chords, enabling what we may hear as minor thirds or slightly flattened major thirds sitting comfortably over major thirds played in the accompaniment. From a psychoacoustic point of view, there is more tolerance for pitch discrepancies and harmonic dissonances in higher registers than there is in lower registers, a well-known phenomenon that stems from the overtone series which has been thoroughly exploited by composers and arrangers. And historically, as will be apparent from the discussion below, the flattening of these thirds in the upper register can be traced to early country blues practice.

Titon has tabulated the pitches used in the vocal lines in his study of early country blues performances recorded in the late 1920s, concluding that the best way to describe so-called blue notes is in the form of 'pitch complexes' centred around the third, fifth, seventh and tenth, collectively spanning the range of a tenth (see Example 1). ${ }^{8}$ Thus the blues scale really consists of four groups of pitches and their microtonal inflections, two of them based on the third but separated by an octave. Interestingly, in Titon's (1994) sample of forty-eight transcriptions, the most frequently found pitch in the lower third complex is a major third (201 out 346 pitches) and in the upper third complex it is a minor third (108 out of 204 pitches). 


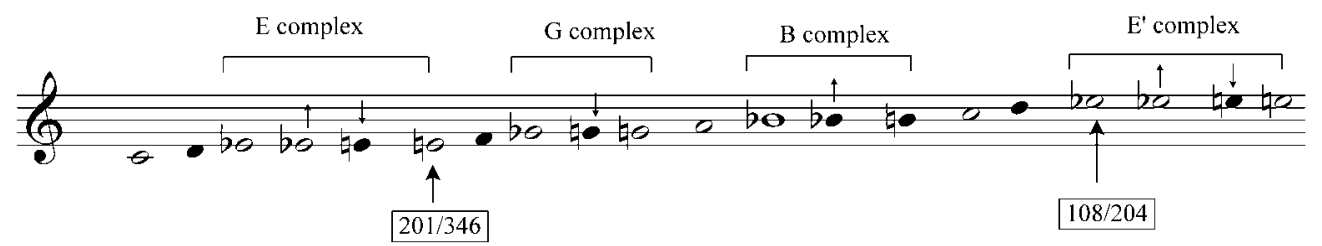

Example 1. Titon's downhome blues scale.

This may help explain how the interval configuration of the seventh chord with a sharp ninth has such appeal, since the sharp ninth, usually voiced an octave higher than the major third, can be heard as the flat third commonly associated with the upper third complex while the major third relates to the lower third complex. In other words, the pitch configuration of the chord represents a significant portion of the tonal markers of melodic activity in the blues idiom. ${ }^{9}$

\section{Flexible pitch relationships and an open texture}

In Hendrix's music, and, for that matter in most blues-based rock music, relationships between voice, guitar and bass are more defined through rhythm, metre and a basic outlining of the chord progression through root movement than they are through structured and goal-oriented voice leading. Chord sequences devised and played on guitar tend to rely on parallel movement, with fifths and octaves deliberately and openly exposed, in many instances functioning more as patterns that establish coherence through repetition than progressions which rely on tension-resolving voiceleading. Moreover, in Hendrix's broken-chord style, chord fragments are strung together with suspended fourths and seconds through a very loose and fluid articulation and distorted sound. A case in point is the rhythm guitar track on 'May This Be Love', where single note passages, dyads and triads mix freely, creating a harmonically open and ambiguous terrain (see Example 2). ${ }^{10}$ And to add to the tonal mix, an electronically processed lead guitar line (Guitar 1) weaves in and out of the texture through slides and vibrato articulation.

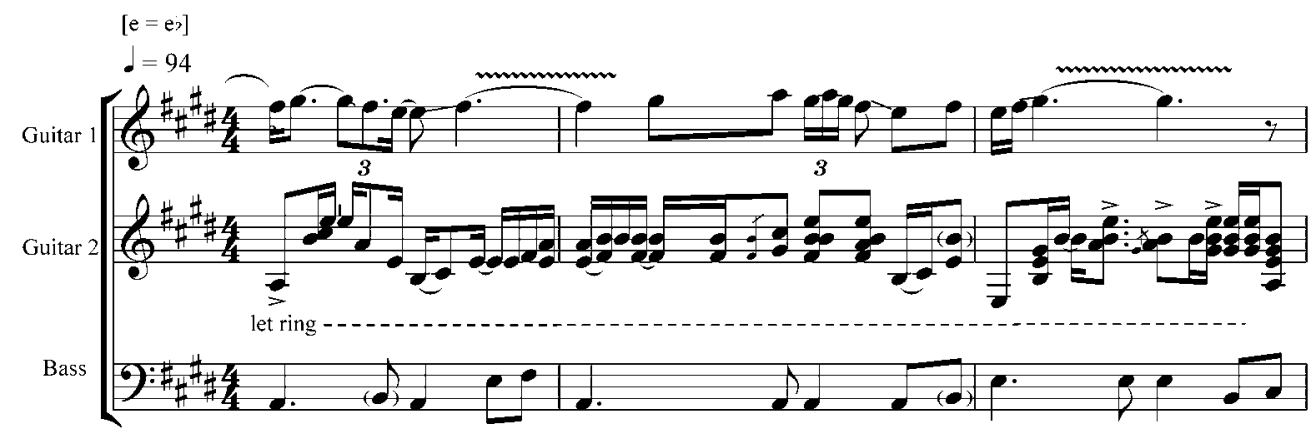

Example 2. 'May This Be Love' (1967) [2:04 AYE 186:I:1].

Hendrix's vocal lines, often a rhythmically nuanced mix of half-spoken and half-sung phrases, are characterised by falling lines often ending with a minor third resolving to the tonic, very much following traditional blues phrasing. ${ }^{11}$ There are 
many instances of unison, heterophonic and quasi-contrapuntal relationships between bass and guitar, and, indeed, Hendrix often instructed his bass players on what to play since he had a clear idea of how he wanted the final texture to sound. But in much of Hendrix's music it would be presumptuous and misleading to look at these relationships as structured and goal-oriented voice-leading. ${ }^{12}$ Melodic motion, in both guitar and vocal parts, tends to follow harmonic rhythm and chord patterns, but in the context of blues performance practice these patterns do not govern pitch content to the same extent as they do in, say, common practice tonality. ${ }^{13}$ In Hendrix's music, pitch relationships exhibit a great variety in terms of adherence to the chord tones of an underlying harmony, both in vocal and guitar lines. The point is that in Hendrix's music we are witnessing a very open texture where many different pitch relationships can co-exist without disturbing each other. Electronic distortion, fluidity and variety in attack resulting in greatly varied dynamics between parts, and set within the harmonically ambiguous framework of the blues, all make for a very expansive and dynamic tonal environment.

\section{Self-standing harmony}

In discussing harmonic practices of the 'golden era' of American song-writing, Allan Forte describes the 'assimilation of blue notes' as 'a very special and characteristically American musical development', illustrated by examples from the likes of George Gershwin and Harold Arlen (Forte 1995, p. 8). While most of his examples rely on voice-leading principles as a means of connecting the blue notes with traditional chord tones in adjacent harmonies, he also makes a point of mentioning that some chords which incorporate blue notes can only be seen as 'self-standing harmony' (ibid., p. 10). This phrase usefully describes seventh chords and their extensions in blues and rhythm-and-blues traditions, since their use can range from ornamental to structural. In blues harmonic practice, unresolved tritones can appear over any root, sometimes generating an impetus for motion and sometimes not. A one-chord blues can be based on a seventh chord over a repeating bass figure, and can easily accommodate extensions beyond the seventh. The addition of the sharp ninth merely adds colour to the tonic in this case, rather than a tension requiring resolution. In Hendrix's music, the sharp ninth sound often occurs on the tonic or dominant, giving it a functional role that goes beyond self-standing harmony, but there are also many instances in which the chord makes an isolated appearance, acting as a kind of signature. And as will be apparent through some of the ensuing examples, there are also instances in which the chord is alternated with the natural ninth in passages where chord qualities are freely mixed, further demonstrating the flexibility with which it can be used.

\section{Blues, flexible pitch relationships, and self-standing harmony}

In summary, in such a harmonically open and ambiguous environment as that established in Hendrix's music, chords or voicings that can stand on their own are entirely acceptable and even desirable. The sharp ninth sound, as an instance of such a self-standing harmony, furthermore can be said to have a strong tonal and registral connection to the blues idiom. An emphasis on timbre, with its concomitant blurring of pitch relationships, and rhythm, with its potentially detractive effect, can smooth over events which under different circumstances would sound unsatisfactory. There 
is a clear link between the blues and the sharp ninth sound, and in one sense we could say that the sound expresses a defining feature of the blues, which most certainly includes the ambiguous nature of the third. Whether conceived as self-standing or harmonically functional, with or without an expectation to resolve, the sound evokes a strong and concentrated blues feeling.

\section{Early appearances of the sharp ninth sound}

Instances of the seventh chord with a sharp ninth appear with some regularity in blues and rhythm-and-blues of the 1950s and 1960s, but guitarist Billy Butler's use of the chord in Bill Doggett's 'Hold It' (1958), subsequently popularised by James Brown in the early 1960s as a 'break tune', proved to be so memorable that musicians began referring to it as the 'Hold It' chord, at least until Hendrix 'appropriated' it through 'Purple Haze'. ${ }^{14}$ It is not surprising that musicians latched on to the chord through Doggett's recording, since Butler's crisp tone combined with a simple and effective voicing clearly defines the opening of the piece (see Example 3 ). ${ }^{15}$

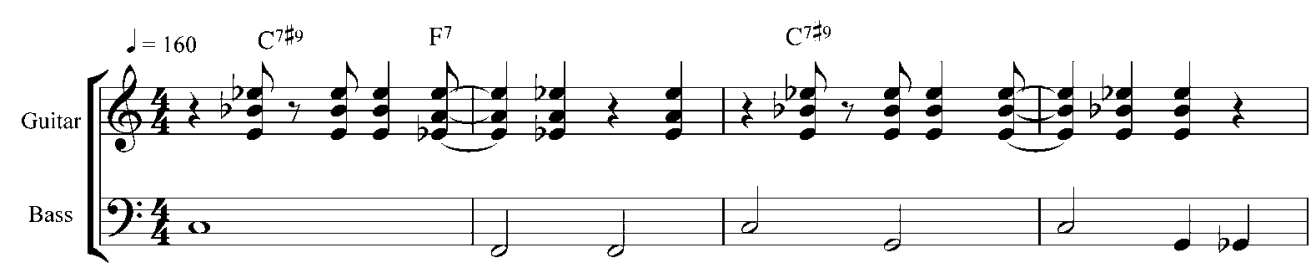

Example 3. Billy Butler's chord changes on 'Hold It'.

Eventually the chord entered the vocabulary of early British rock, an early recorded example being the Kinks' 1964 cover of Chuck Berry's 'Beautiful Delilah' (1958). By the mid-1960s, the Beatles had also incorporated the sound into their music, featuring it prominently in 'The Word' from their 1965 album Rubber Soul. ${ }^{16}$

When and where Hendrix began to incorporate the sharp ninth sound into his playing is not clear since his early rhythm-and-blues years are poorly documented. But given the fact that he toured extensively with several of the leading rhythm-andblues acts during the early 1960s, it seems reasonable to assume that it would not have taken long for him to incorporate it into his playing. The earliest recorded evidence we have of his use of the chord is on the Isley Brothers 'Testify, Parts 1 and 2' (1964), one of the few known recordings he made in the years prior to his discovery in 1966, and we can only assume that since he was trotting out the chord as part of his first major recording, that he must have already been thoroughly enamoured with its sound (see Example 4). In 'Testify', we can hear the chord in an antiphonal response to the shouting vocal line, the sharp ninth sound unmistakably coming through. ${ }^{17}$

He also appeared on a number of recordings in late 1965 and early 1966 with Curtis Knight where strongly accented instances of the sharp ninth sound can be clearly heard leaping out of the rhythm section on 'Last Night' and 'Shotgun'. Similarly, in a mid-1966 session with saxophonist Lonnie Youngblood called 'Under the Table', Hendrix plays the chord, leaving no doubt that he had developed a fondness for it long before his recordings with the Experience in London, beginning in late $1966 .^{18}$ 


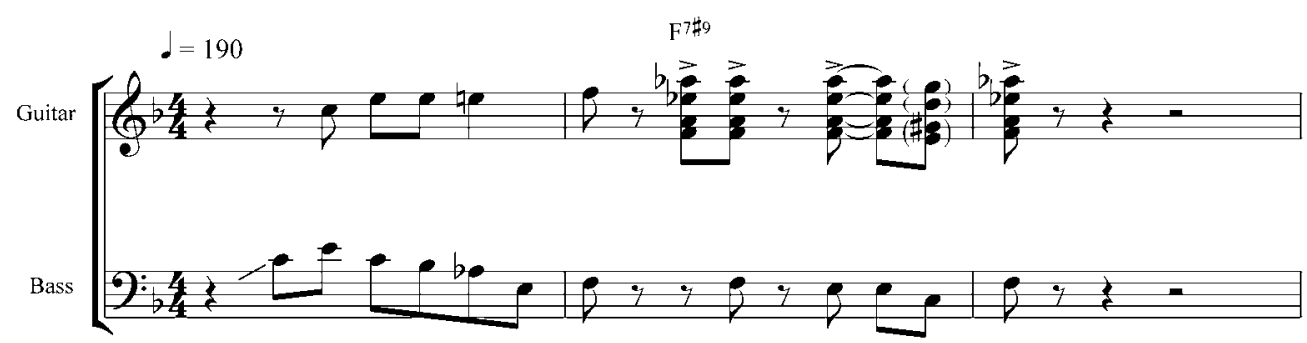

Example 4. 'Testify' (Isley Brothers, 1964) [0:20].

\section{The sharp ninth sound in Hendrix's music}

There is a variety of instances of the sharp ninth sound in Hendrix's music and a corresponding variety of ways in which these instances can be classified. Two categories, which are not mutually exclusive, present themselves readily: (i) instances related through voicing, register and timbre, and (ii) instances related through harmonic function. In many instances, the chord plays a key role in establishing the tonality for a given piece, particularly when it acts as a tonic, but there are also instances where it appears to be more ornamental and at times even incidental. The examples that follow have been sorted by harmonic function and voicing, but it will be apparent that there are many more variables, extensive and kaleidoscopic.

\section{Full voicings with tonic function}

In Hendrix's music, the majority of instances of the sharp ninth sound occur on the tonic, reinforcing the notion that seventh chords do not need to function as dominants in the context of a blues-based style. Hendrix's most well-known use of the sound is in 'Purple Haze', where E7 $\$ 9$, strummed loosely in open position but with heavy distortion added, clearly sets the tone for the piece (see Example 5). Interestingly, because of heavy distortion and a loose, undefined articulation, individual notes of the chord are very difficult to hear out, and the identity of the chord can be perceived just as much through timbre and register as it is through pitch content.

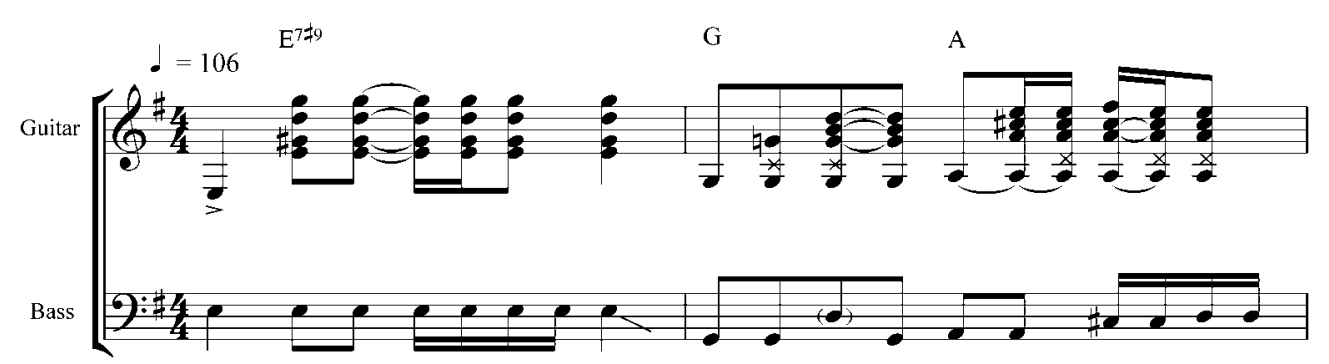

Example 5. 'Purple Haze' (1967) [0:23 AYE 36:II:3].

The basic chord progression for ‘Purple Haze' is I E7\#9 / / / / G / A / I, with $\mathrm{G}$ and A played as contrasting, unadorned triads in bar-chord form. ${ }^{19}$ Functionally, this translates to I-bIII-IV, a common pattern used by rhythm-and-blues players derived from a doubling of major triads based on the minor pentatonic scale. ${ }^{20}$ The addition of $b 7$ and $\sharp 9$ to the I chord adds both motion (V7 of IV) and colour, which, 
timbrally, receives an extra dissonant boost through the distortion produced by a fuzz box and a very loose strumming technique, making it blurred yet still recognisable. The vocal line in 'Purple Haze' centres on $g$, although Hendrix's half-spoken and half-sung style of singing tends to de-emphasise pitch in favour of rhythmic nuance. This instance of the chord is the most well known and emulated example of Hendrix's use of the sharp ninth sound, helped by the fact, of course, that it occurs in one his most well-known pieces, but as we will see in the ensuing examples, there is considerable variety in voicings and applications.

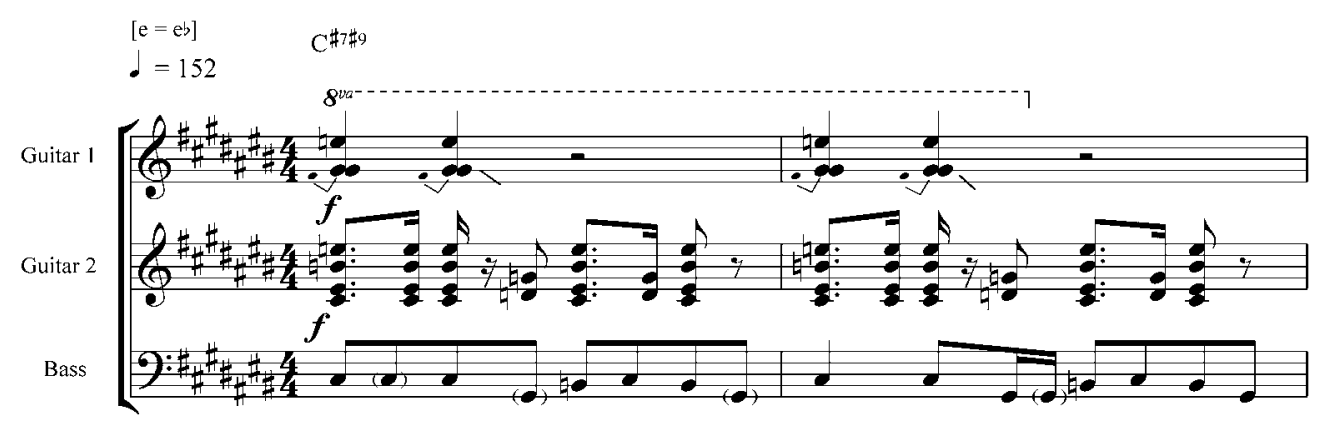

Example 6. 'Ain't No Telling' (1967) [0:02 ABL 54:I:3].

Layered guitar parts in 'Ain't No Telling', each articulated differently and mixed at different volume levels, produce another hearing of the sharp ninth sound. Here the sharp ninth (notated as $e$-natural), in combination with a unison bend into the fifth (Guitar 1), stands out against a more subdued and evenly strummed and fully voiced $C \sharp 7 \# 9$ (Guitar 2) by virtue of its attack (see Example 6). We hear the sharp ninth being lifted out of the full voicing in the steady and consistent rhythm guitar accompaniment which is present throughout the piece, an aural highlighting of the bent fifth and sharp ninth. As we will see in some of the other examples, Hendrix more often pairs the sharp ninth with the flat seventh as a means of establishing the sharp ninth sound, particularly in the upper register, but here, because of a steady rhythm guitar track in which the full voicing is almost always present, he is able to enrich the sound by introducing the bend into the fifth. ${ }^{21}$

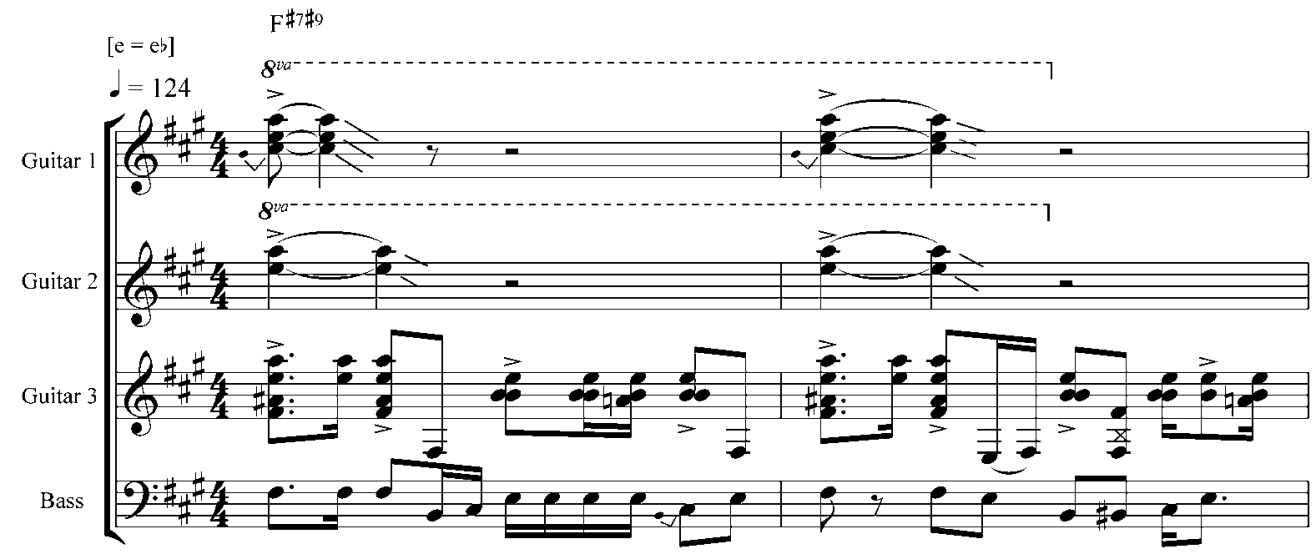

Example 7. 'House Burning Down' (1968) [0:30 ELL 345:I:1]. 
'House Burning Down' uses the same principle of creating layers with different levels of volume and timbral contrast, with yet another guitar part (Guitar 2) added to emphasise the $b 7-\$ 9(e-a)$ interval (see Example 7). What makes this instance different from 'Ain't No Telling' is the articulation of the top part, where a heavily accented $\mathrm{C} \#-\mathrm{e}-\mathrm{a}$ ends with a slide, creating a distinct sound shape that leaps out of the texture. Other instances of this technique demonstrate that Hendrix's use of this register and articulation is closely associated with his concept of the sharp ninth sound.

Hendrix's virtuosic exploitation of timbre is so persuasive that single note passages can sound as if they are affiliated with particular harmonies. He used Fender Stratocasters, which produce a tone very rich in upper partials and transients, and combined with amplifier distortion, feedback and effects such as phase shifting, electronic octave doubling, and the wah-wah pedal. The result was that his singlenote lines carried with them a host of implicit harmonic content. Complex sounds often were simply single-note lines or dyads, which in their notated form seem far removed from what we hear. ${ }^{22}$ In 'If Six Was Nine', Hendrix continuously alludes to the dissonance associated with the sharp ninth sound through heavily accented and distorted riffs that centre around $g$, but he only actually plays the flat seventh sharp ninth chord briefly in its entirety (see Example 8).

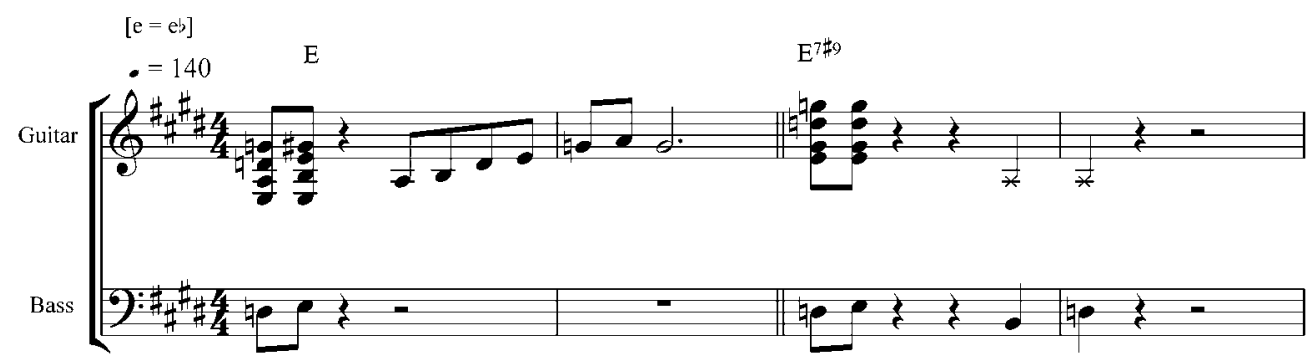

Example 8. 'If Six Was Nine' (1967) [0:51 ABL 76:II:2].

As the piece moves into a more experimental and jazz-based groove, Hendrix uses ninth and sixth chords with looser articulation, in effect dissipating the earlier allusions to a sharp ninth sound. This shift to (natural) ninth chords and its differing emotive effect is an early example of Hendrix's juxtaposition of the two types of sonorities, a device he used more in his later work.

\section{Incomplete voicings with tonic function}

Anyone familiar with Hendrix's music would be tempted to categorise the opening voicing of 'Foxey Lady' as a typical sharp ninth sound even though the chord that is actually being played is $\mathrm{F} \sharp \mathrm{min} 7$, thus raising the question as to what is necessary to establish a sharp ninth sound (see Example 9). A distinguishing feature of this incomplete voicing is the combination of register, articulation and dynamics: it is played loud, high, distorted and with a vibrato or 'shake'. Also pertinent to this instance is the production of a clearly audible $a$ through feedback in the opening of the piece, preceding the first iteration of the minor seventh voicing (not shown in the transcription). ${ }^{23}$

As in much of Hendrix's music, harmony, in the sense of explicitly delineated vertical sonorities, is more implied than stated. Here, the emphasis is on establishing 


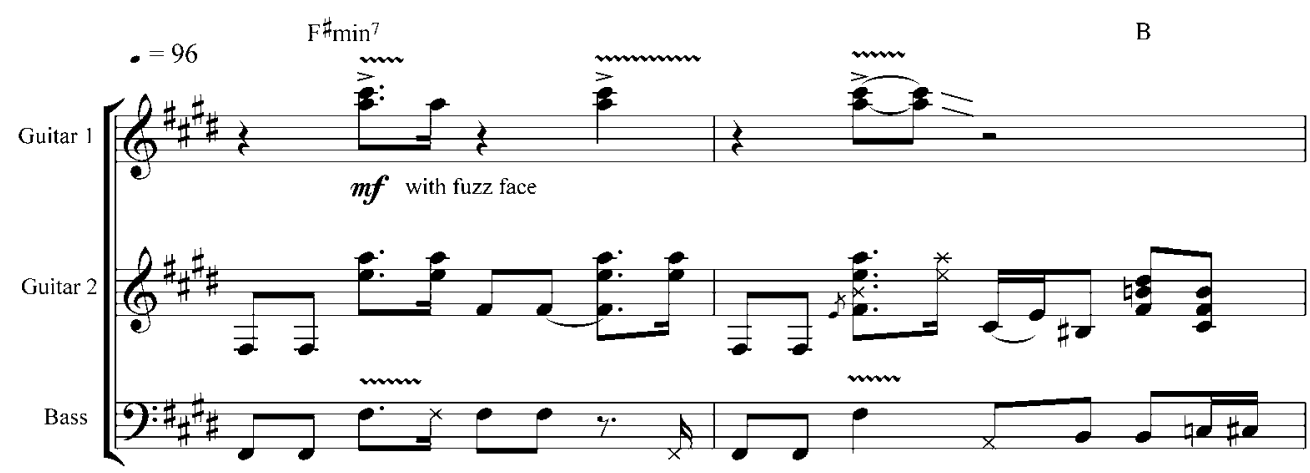

Example 9. 'Foxey Lady' (1966) [0:11 AYE 91:I:1].

the $f \#$ in the bass and the sharp ninth in the $a-c \#$ dyad (Guitar 1), which is in the upper register, leaving the middle register open, where the major third would normally appear. With the $e-a$ dyad in the second guitar part, the sharp ninth voicing is split between two overdubbed guitar parts, but a heavy attack and vibrato favours hearing $a-c \#$ over $e-a$. In other words, the $b 7$ is present, but overshadowed by the fifth. In the chorus section immediately following the opening, Hendrix plays the major third, $a$ \#, as part of a fully voiced $F \sharp$ maj bar chord, in effect resolving some of the initial tonal ambiguity of the piece (see Example 10).

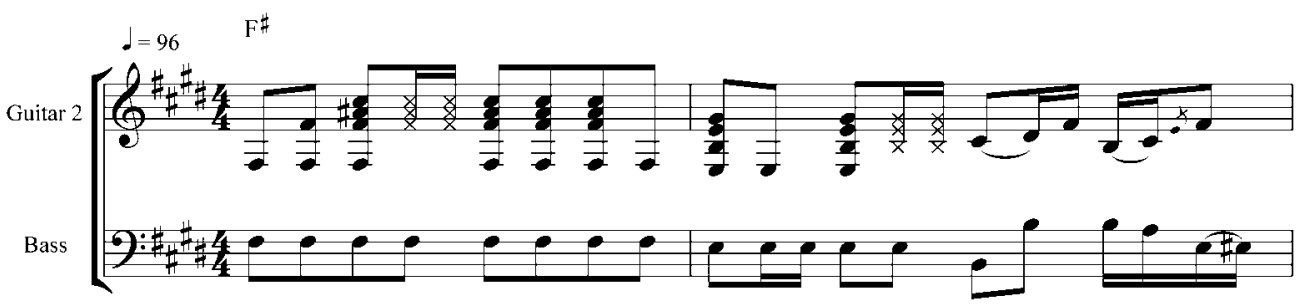

Example 10. 'Foxey Lady' (1966) [0:40 AYE 92:I:3].

Similar to 'Foxey Lady' and 'Ain't No Telling' in terms of articulation and emphasis on the fifth is the beginning of the chorus section of 'I Don't Live Today', but this instance acts as the signpost of a formal demarcation. Before the chorus begins though, the brief opening chord sequence of the piece contains the $d \sharp$ as part of B7 and Bmaj6 voicings, in effect framing the Bmin7 voicing that follows in the chorus as part of an implied major tonality (see Example 11).

Between the opening chords and the beginning of the chorus (i.e. the first verse), harmonic content dissipates as single note lines and manipulation of timbre through feedback and vibrato bar dives come to the forefront. The Bmin7 voicing that follows

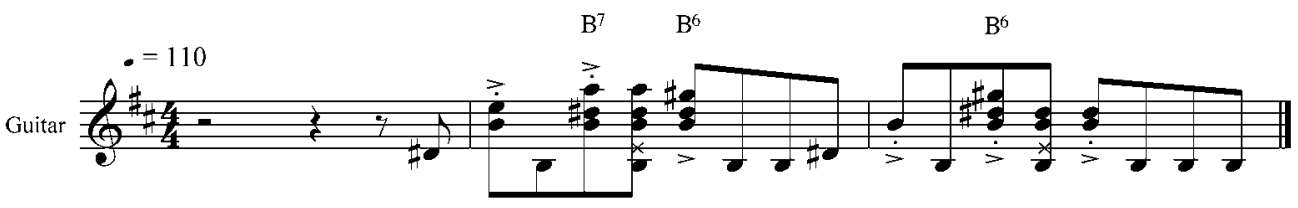

Example 11. 'I Don't Live Today' (1967) [0:01 AYE 159:I:2]. 
is heard as a sharp ninth chord (see Example 12). As in 'Ain't No Telling', this instance of the sharp ninth sound distinguishes itself by the use of a unison bend into $f \#$ (the fifth), with the sharp ninth sound buried in the mix. And as with 'Foxey Lady', articulation, dynamics and register play significant roles in creating a distinctive sound. Because of a loud and high placement and 'falling off' slide, it is possible to hear both voicings as having the same quality.

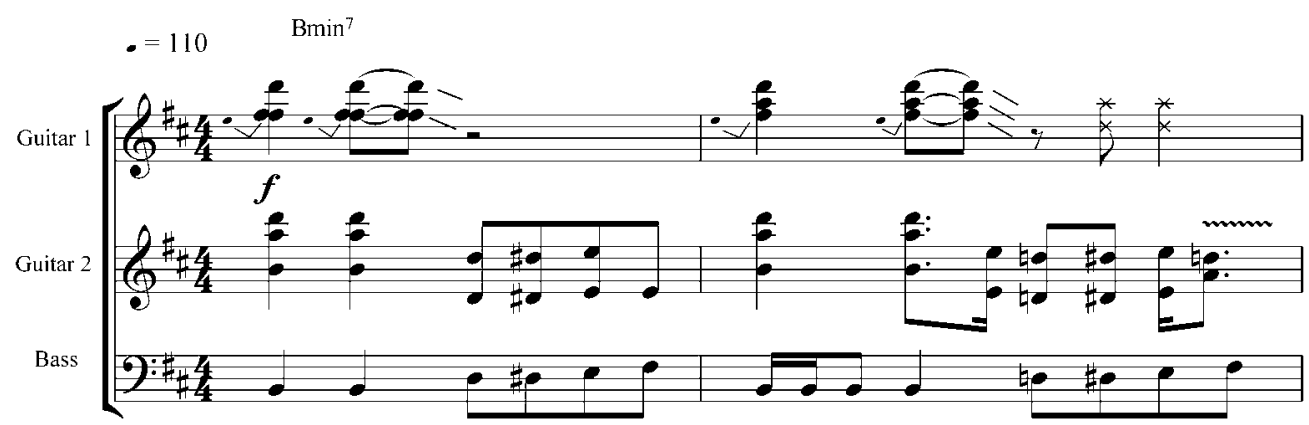

Example 12. 'I Don't Live Today' (1967) [1:01 AYE 163:I:1].

Register and articulation combined clearly play a strong role in associating the incomplete voicings of 'Foxey Lady' and 'I Don't Live Today' with the sharp ninth sound, but articulation alone can also create an association. In the introduction to 'Spanish Castle Magic', a heavily accented C\#min7 voicing preceded by repeated instances of the minor third or sharp ninth in the lower octave creates an association with the sharp ninth sound through articulation (see Example 13). ${ }^{24}$ Without the heavy accenting, the voicing would simply be heard as a minor seventh sound. This association becomes clear when the fully voiced $C \sharp 7 \$ 9$ briefly appears later in the piece, about halfway through the second verse. ${ }^{25}$

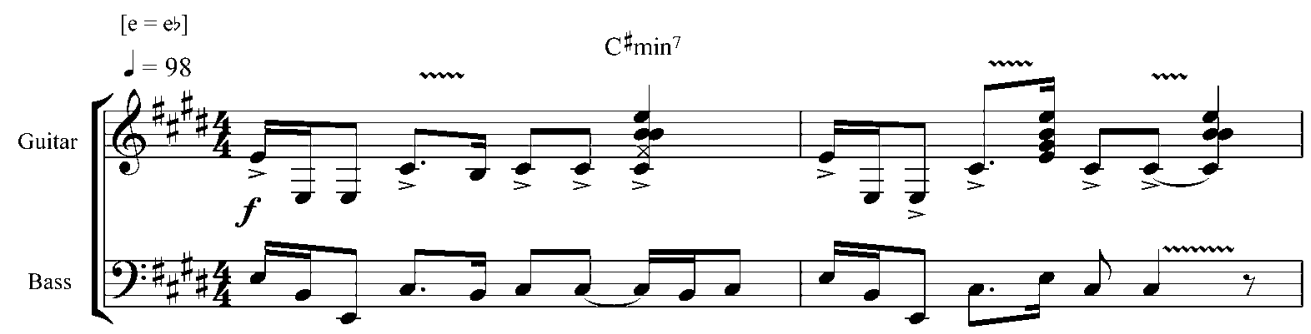

Example 13. 'Spanish Castle Magic' (1967) [0:03 ABL 22:I:2].

In 'Little Miss Lover' the sharp ninth sound, in its distilled version represented through the $b 7$ and $\sharp 9$, derives its root and harmonic function solely from the bass guitar, while the rhythm guitar associates with the drum pattern through deadened string 'chugs' (see Example 14). ${ }^{26}$ Both tonic and lowered mediant use the sharp ninth sound, effectively oscillating between two tonal centres, although these tonal centres are almost incidental to the rhythmic 'riff' that characterises the tune. We could say that tonal material is secondary to rhythmic material in this instance. As with 'Ain't No Telling' and 'House Burning Down', there is a distinct separation of the sound 
from the background texture, or aural highlighting, but in this case, the background is primarily non-pitched percussion sounds.
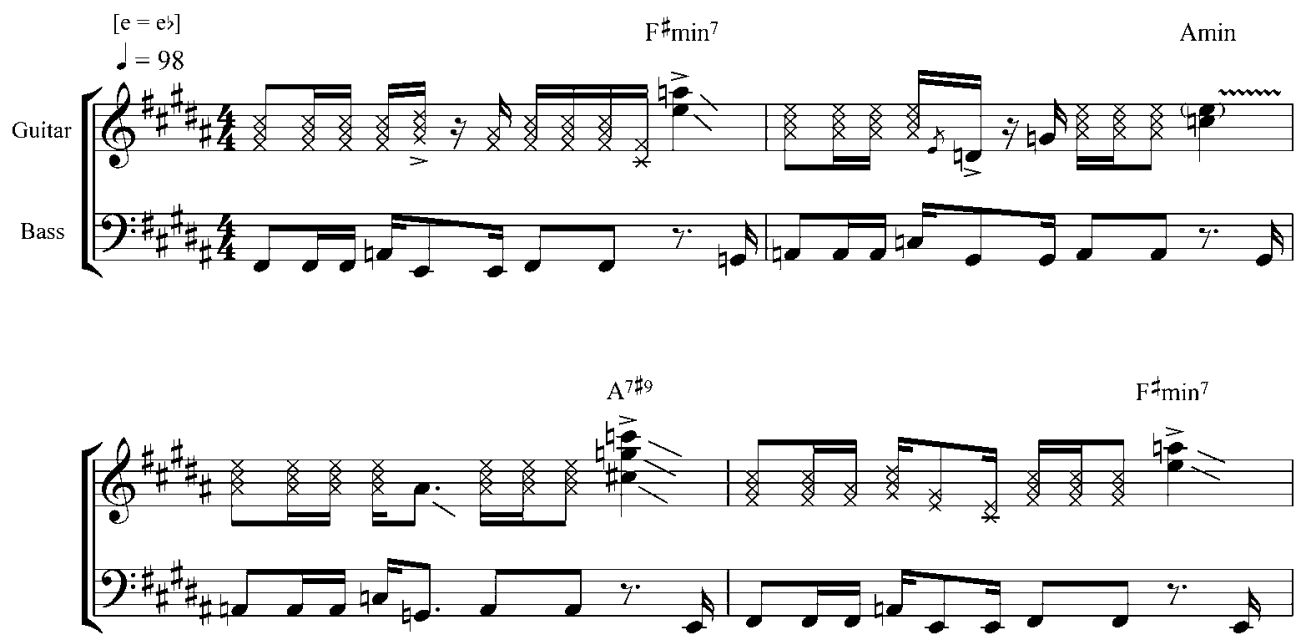

Example 14. 'Little Miss Lover' (1967) [0:18 ABL 157:II:2].

Hendrix's extended studio improvisations on 'Voodoo Chile' provide some insight into how he used the sharp ninth sound in instances where it is not an explicit or essential component of the composition, unlike the preceding examples (with the exception of 'If Six Was Nine') where omission of the sound would result in a radically different overall character for the composition. 'Voodoo Chile' is a one-chord twelve-bar $a a b$ blues in E with a brief turnaround using the chords $C$ and $\mathrm{D}$ to get back to E. Hendrix rarely plays more than two notes at once, with guitar phrases moving in and out of unison with the vocal line. The incomplete voicing shown here, distinguished through rhythmic interplay with the drums, occurs during the end of the organ solo, acting as a cue to wind down in preparation for the next verse (see Example 15). Voicing and register are identical to that used in 'Foxey Lady', but a syncopated rhythmic placement and loose attack make for a radically different impact.

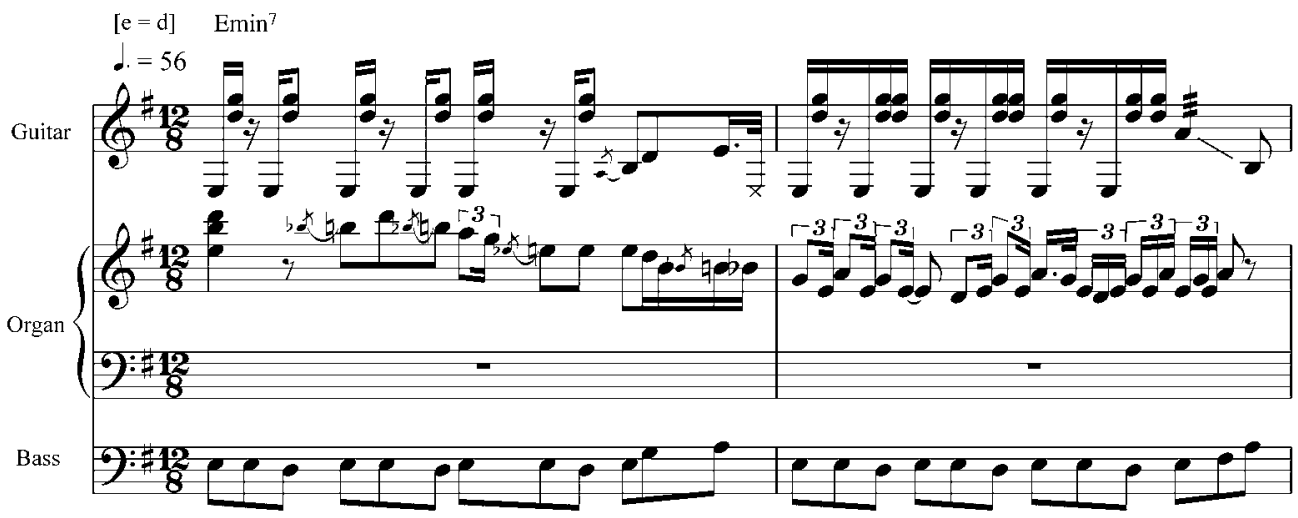

Example 15. 'Voodoo Chile' (1968) [6:36 ELL 62:I:1]. 
Other instances of the sharp ninth sound in 'Voodoo Child' are similarly brief. As if to assert what may be inferred from much of the melodic activity, Hendrix flashes the sharp ninth sound in the upper register amidst mid-register noodlings, a rare appearance of the sound in its vertical manifestation (see Example 16). It is clear that this highlighting is the result of post-performance mixing, since stereo panning and echo match the rhythmic figure of the segment. Hendrix was very much involved in the mixing and production process during the making of Electric Ladyland, of which 'Voodoo Chile' was a part, so it was likely his decision to bring this instance to the forefront.

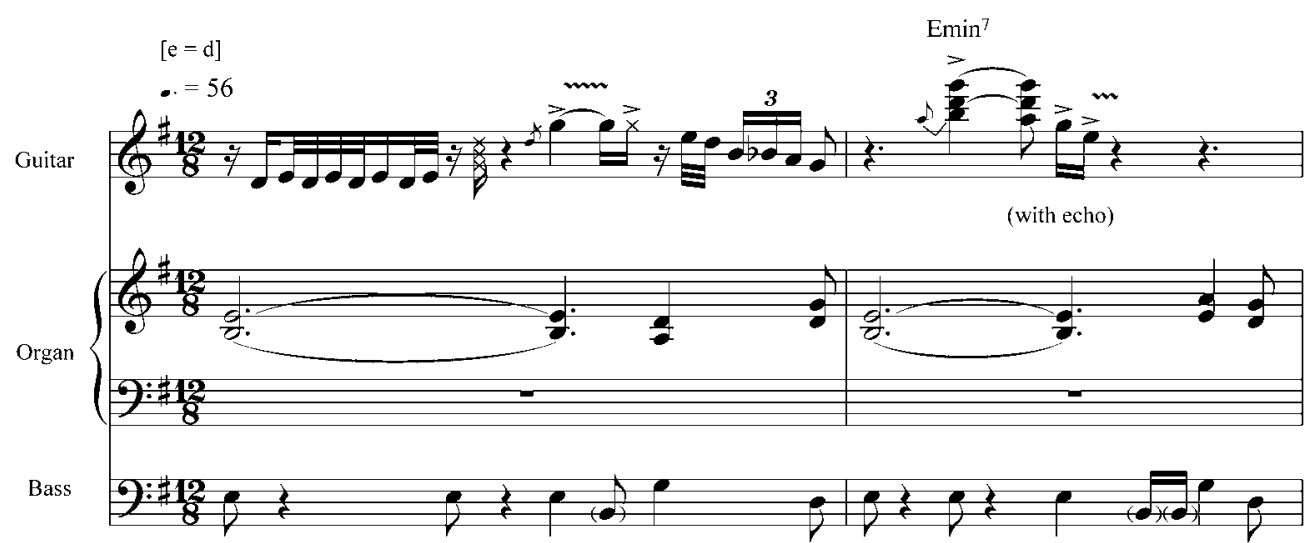

Example 16. 'Voodoo Chile' (1968) [7:20 ELL 65:I:1].

As the piece comes to a close, the full voicing appears briefly in a pseudo dominant function preparing the turnaround I C / / / I D / / / E / / / I E / / / I (bVI - bVII - I), which leads into the final guitar solo (see Example 17). The voicing used here is identical to 'Purple Haze', and since it has a similar degree of distortion, it sounds the same, but it is almost ornamental in that it could easily be omitted without significantly disturbing the harmonic intent. ${ }^{27}$

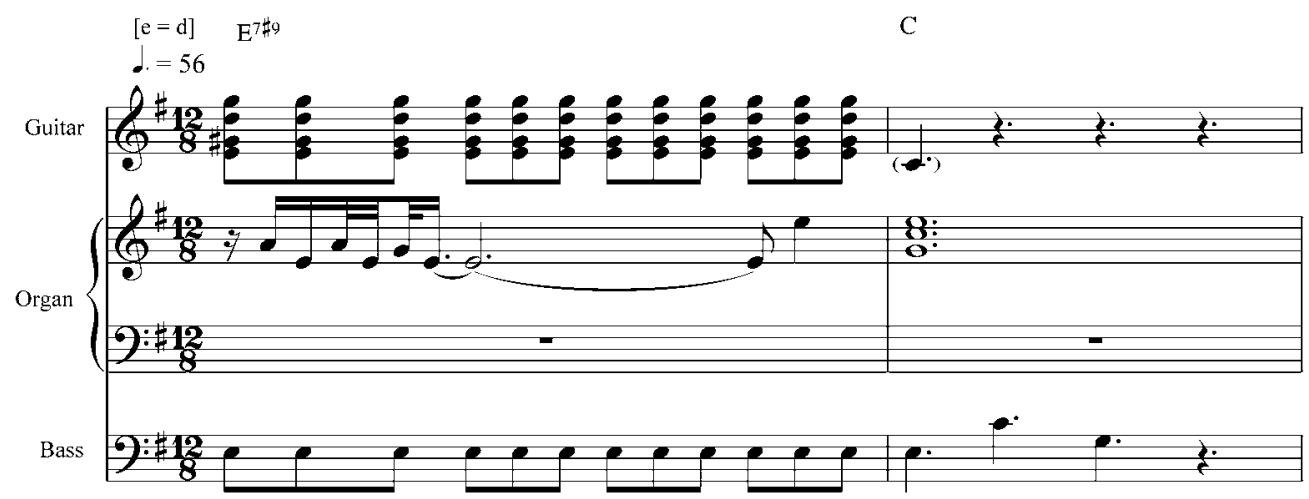

Example 17. 'Voodoo Chile' (1968) [12:05 ELL 86:I:1].

In 'Crosstown Traffic' the tonic chord C $\#$ is voiced as a minor seventh chord, while the subdominant $\mathrm{F} \#$ is a fully voiced flat seventh sharp ninth chord (see 
Example 18). This is an instance where it is very clear that the intended harmony is major rather than minor, but the omission of the third is not inadvertent, as might be the case in some instances, since the added piano track also uses a voicing without the major third. ${ }^{28}$ 'Crosstown Traffic', like 'Purple Haze' and 'Foxey Lady', is suffused with the sharp ninth sound even though the full voicing occurs only at selected points, and it is all the more apparent that the minor seventh voicing is better heard as a sharp ninth voicing with the major third omitted.

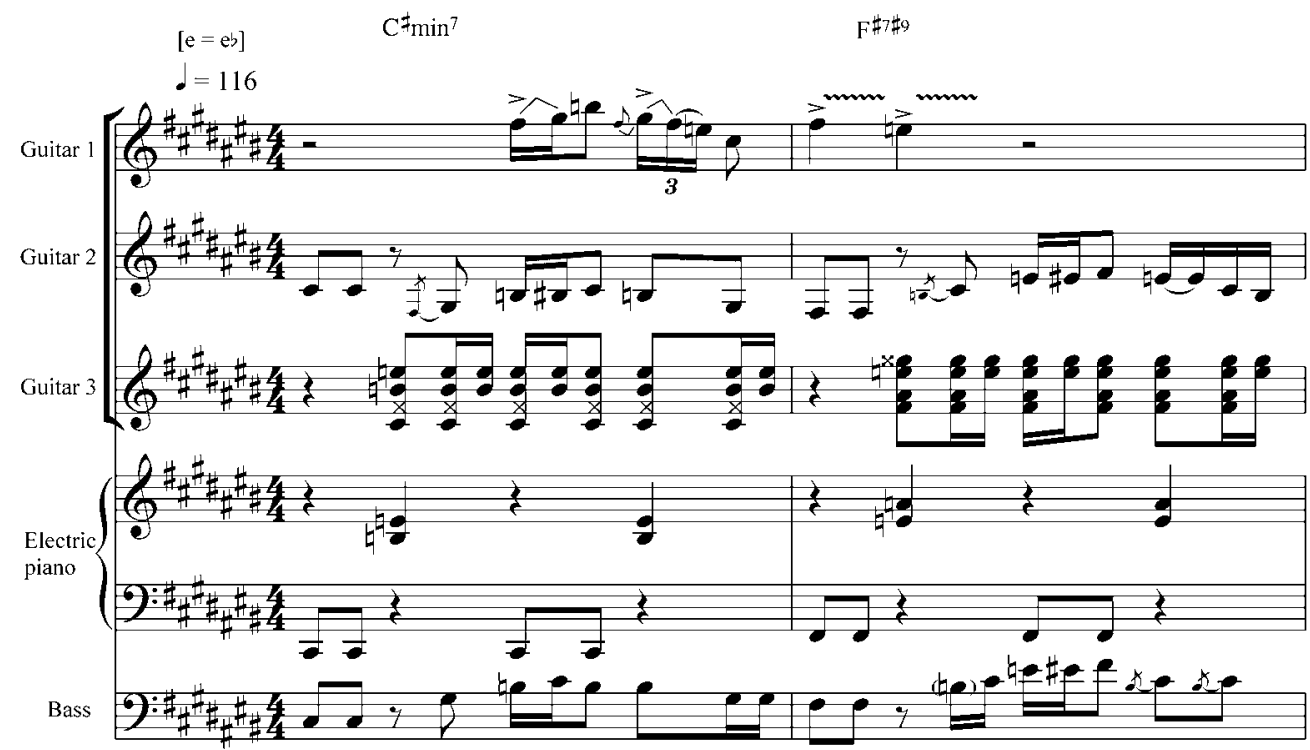

Example 18. 'Crosstown Traffic' (1968) [0:04 ELL 14:I:1].

\section{Full voicings with dominant function}

Far less common in Hendrix's music is the flat seventh sharp ninth chord actually functioning as a dominant. In 'Can You See Me?' the chord appears very briefly, but consistently, at the end of each verse, clearly functioning as a dominant chord propelling the verse to its ending (see Example 19). This is all the more effective because of the bare fifths and octaves style of chording ('power chords') used throughout the rest of the tune, and unlike Hendrix's other tunes where chord extensions are sprinkled throughout as a result of the broken chord style of rhythm guitar playing. Articulation and timbre in this instance are subdued, with the individual pitches clearly exposed, allowing the chord to be heard in its entirety. And unlike many other instances, voice leading follows convention by resolving the third and seventh ( $\mathrm{e} \#$ and b) of $C \sharp 7 \sharp 9$ to the root and third ( $f \#$ and $a \sharp$ ) of $F \#$.

The opening of 'Stone Free' uses the same tonic voicing (E7 $¥ 9$ ) as 'Purple Haze', but because of its shifting tonal centre, this chord becomes a dominant to the subdominant (A), which in turn becomes a dominant to the new key centre $\mathrm{D}$ in the chorus (see Example 20). With more broken chords and tonal ambiguity (the major third is not consistently present) the chord does not come across with the same forceful ruggedness that the tonic of 'Purple Haze' has.

When the piece moves briefly from this initial tonic $\mathrm{E}$ to $\mathrm{A}$ in the eight-bar section linking verse and chorus, Hendrix clearly articulates the full voicing in the last two 


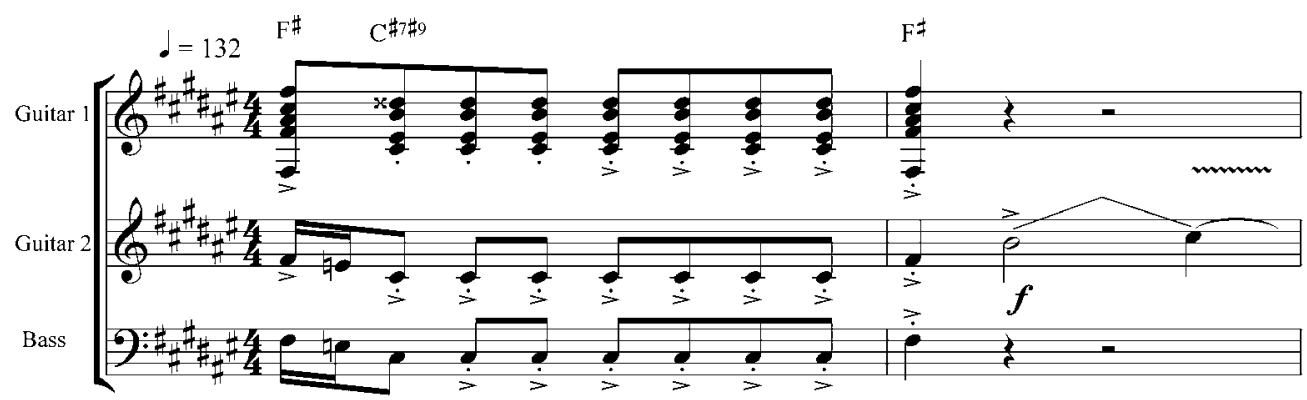

Example 19. 'Can You See Me' (1966) [0:37 AYE 135:II:1].

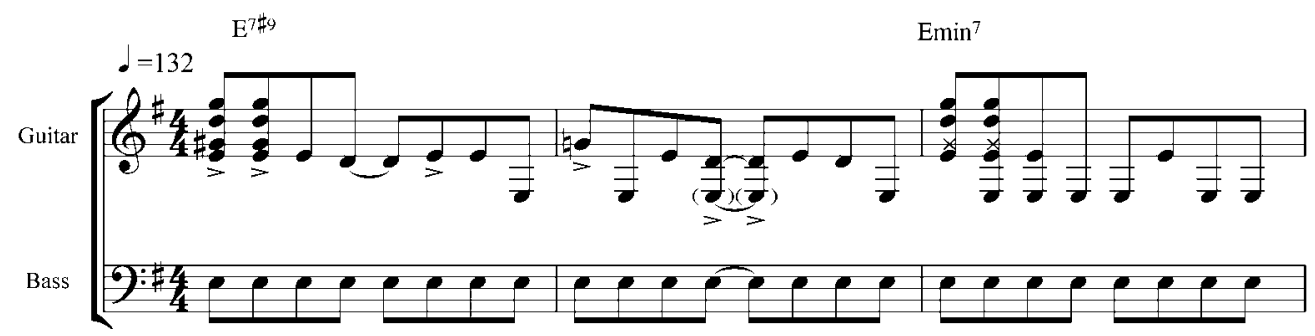

Example 20. 'Stone Free' (1966) [0:07 AYE 20:I:5].

bars, creating a dominant in preparation for the key of D in the chorus that follows (see Example 21). 'Stone Free' demonstrates the versatility of the sharp ninth sound within the context of blues performance practice: by changing articulation and dynamics, even within a phrase, it can easily slip from a 'self-standing harmony' into a harmonically functional role.

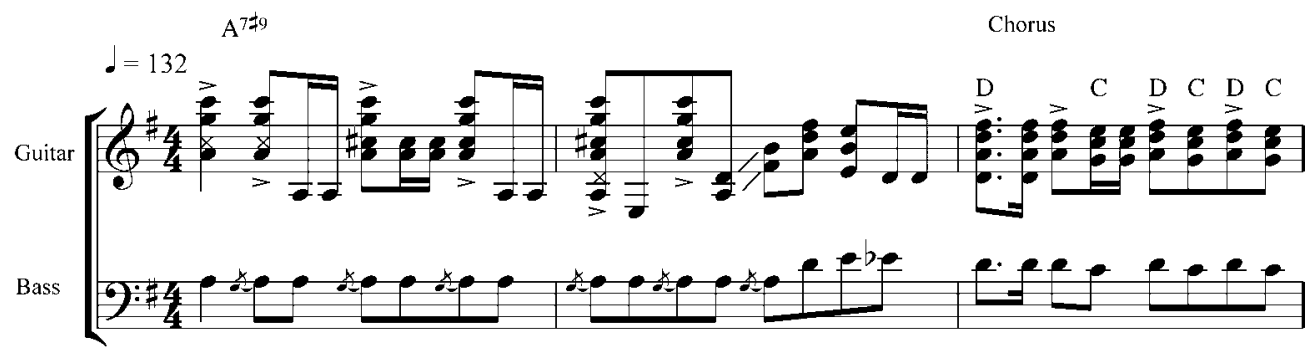

Example 21. 'Stone Free' (1966) [0:50 AYE 23:II:1].

A prime example of Hendrix's innovative approach to composition is his transformation of the twelve-bar blues progression in 'In from the Storm', in which the piece begins on bVII:

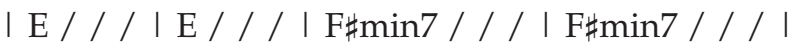

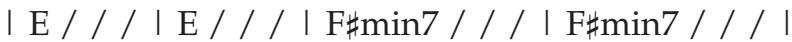

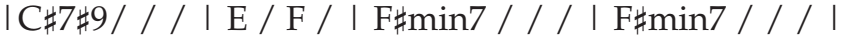

While the flat seventh sharp ninth chord functions as a dominant, it still stands on its own in terms of colour, in stark contrast to the third-omitted voicings for $E$ and $\mathrm{F}$ following it (see Example 22). Hendrix’s voicings for the F\#min7, most of them 
strings of melodically connected dyads, bear none of the features that could relate them to the sharp ninth sound, thereby allowing the fully voiced $C \sharp 7 ¥ 9$ to stand out as a critical and defining point in the structure of the tune.

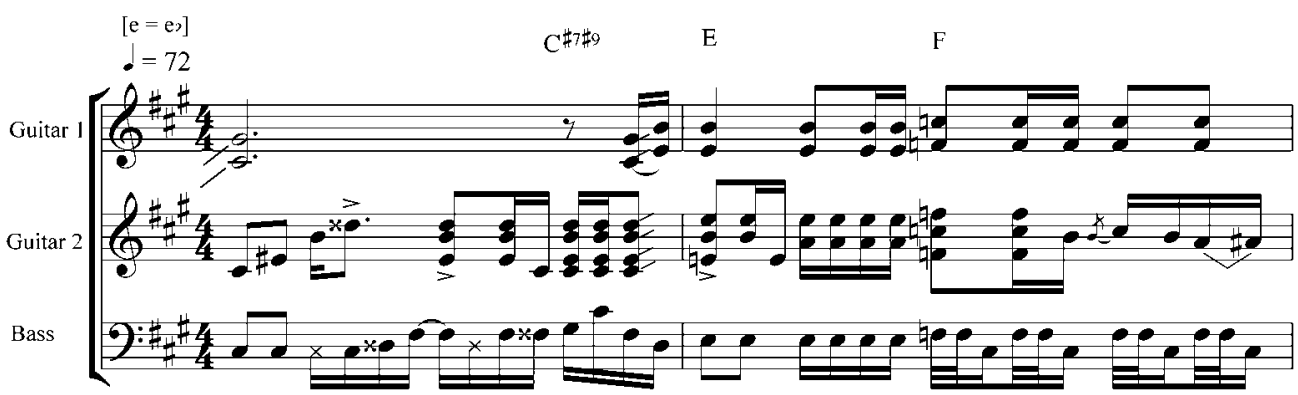

Example 22. 'In From the Storm' (1970) [0:35 FRNRS 281:I:1].

\section{Full voicing with the bVI}

The bVI chord, often functioning as a substitute dominant of the dominant, which resolves on $\mathrm{V}$, can also stand on its own in alternation with the tonic, as is the case in the verse of 'Highway Chile' (see Example 23). As in 'In From the Storm', the bVI7 $¥ 9$ chord is the only instance of a chord with extensions in the piece, with the remaining chords (I, bIII and IV) stripped down to triads or even bare fifths. It is an interesting position for the chord to be in since it hints at the dominant function by virtue of the extensions but moves back to the tonic before actually fulfilling that role. Articulation in this instance is loose and undistorted, with a typical Fender sound providing rich harmonic overtones, and the contrast with the other unadorned chords in the piece is pronounced. Functionally, the chord straddles the line between being heard as some kind of dominant, albeit with an indeterminate goal, and a self-standing harmony that simply provides relief for the tonic.

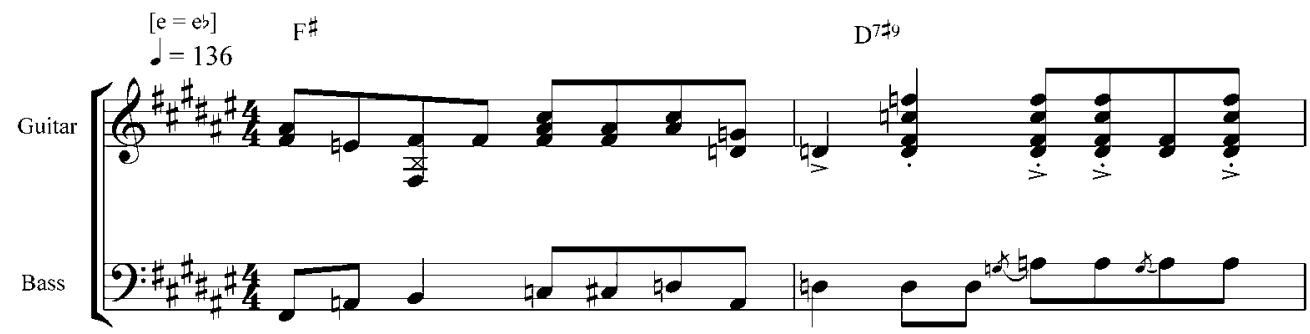

Example 23. 'Highway Chile' (1967) [0:27AYE 77:I:2].

\section{Juxtaposition with natural ninth chords}

A slightly perplexing aspect of Hendrix's music is his very fluid and sometimes unsystematic juxtaposition of flat seventh chords with sharp ninths and flat seventh chords with natural ninths, although the harmonically ambiguous environment clearly supports this type of juxtaposition. In early works from the studio recordings of 1967 and 1968, like 'Purple Haze', 'Ain't No Telling' and 'Foxey Lady', it is rare that ninth chords are alternated with sharp ninth chords. But Hendrix's later studio recordings, during 1969 and 1970, demonstrate a penchant for mixing chord qualities 
freely, especially evident in compositions such as 'Drifting' and 'Angel'. When he did use ninth chords in the early recordings, the prime example being 'Up From the Skies', it was to create a distinct jazz sound, or in 'If Six Was Nine', as discussed earlier, where the transition from a riff-based section to a more experimental section with jazz overtones is indicated through ninth chords. Another early piece, 'Little Miss Lover', with its alternating sharp ninth and ninth chords near the end of the piece, in some ways foreshadowed the mixing of chord qualities in later recordings. A more calculated early example of mixing chord qualities can be found in 'You Got Me Floatin". Throughout the piece, the bass consistently avoids the implied root $a$ by repeating a figure emphasising the minor third $(c)$, flat seventh $(g)$, and fourth $(d)$. After two minutes of more or less third-less harmonies, the beginning of the outro starts off with a suspended fourth followed by a fully voiced sharp ninth sound, and after a chromatic chord sequence, moves into a steady alternation between A9 and Bb9 (see Example 24). ${ }^{29}$ The effect is that the brief appearance of the sharp ninth sound, at least in chordal form, marks a transitional point in the piece where chord qualities begin to mix.
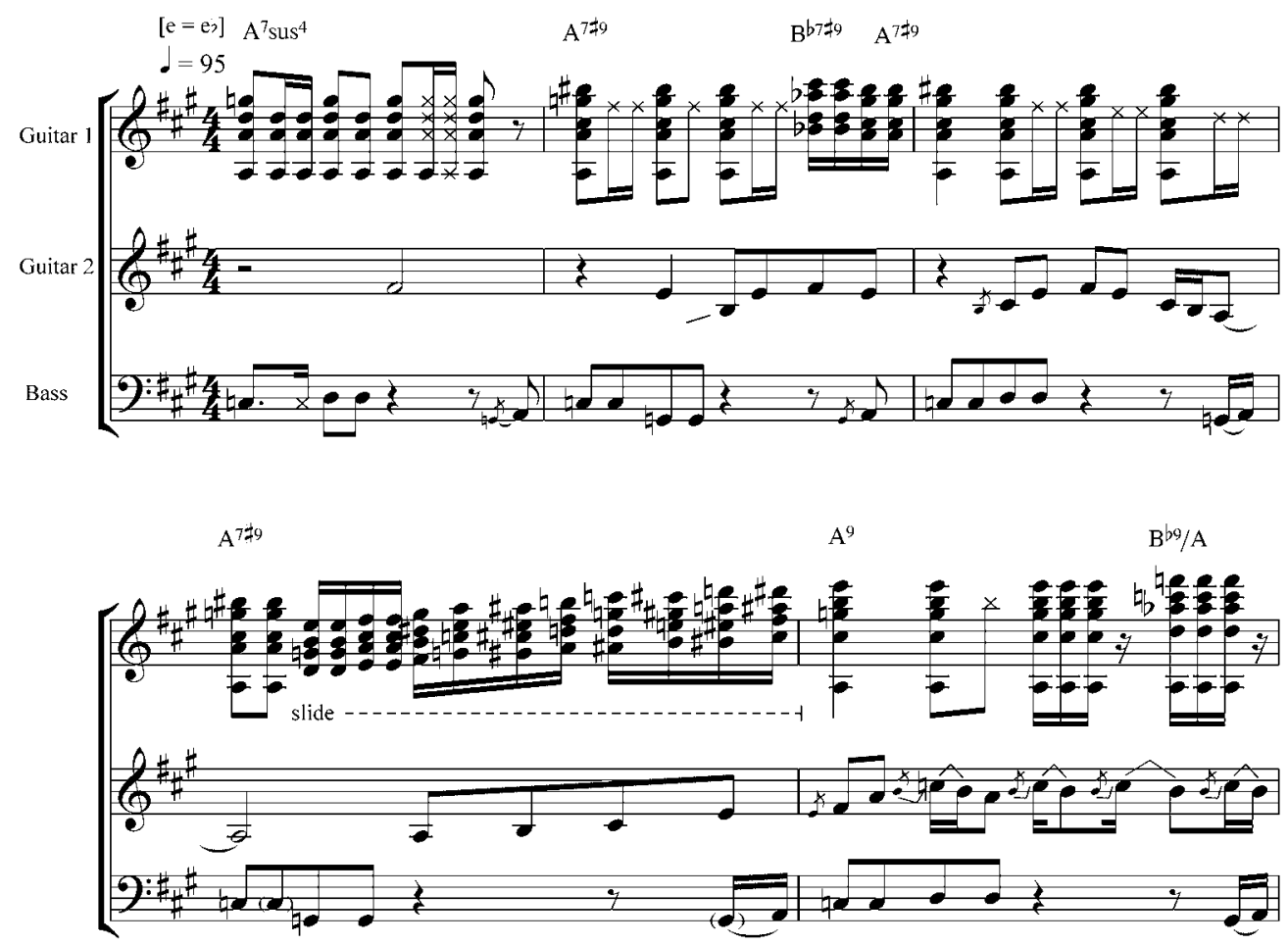

Example 24. 'You Got Me Floatin'" (1967) [2:15 ABL 110:II:2].

The next four examples are all from 1970, the last year of Hendrix's life, a point at which many felt he was searching for new musical directions. The studio work from this period certainly supports this notion, since he had become very much preoccupied with creating more complex arrangements built around multi-tracked guitar parts with meticulously constructed timbral contrasts. ${ }^{30}$ 
'Freedom' is based almost entirely on a single chordal vamp in $C \sharp$, with a bridge in $F \sharp$. During the first verse of 'Freedom', $C \sharp 7 ¥ 9$ alternates with $C \sharp 9$, but the change is buried in a registral shift. Considerable ambiguity remains, though, with dampened fingering for the major third and an accented and 'worried' $e$-natural in the first guitar part (see Example 25). As the piece progresses, neither ninth prevails, due in large part to Hendrix's broken chord technique, with continuous movement between chord tones and non-chord tones. Strings of sixteenth-note dyads, mostly fourths and triads, weave in and out of major and minor harmonies with various chord extensions. But during the last bar of the outro, Hendrix arpeggiates a fully voiced $C \sharp 9$ ( $c \sharp-e \sharp-b-d \sharp-g \sharp)$ chord, as if finalising the alternatives presented throughout.

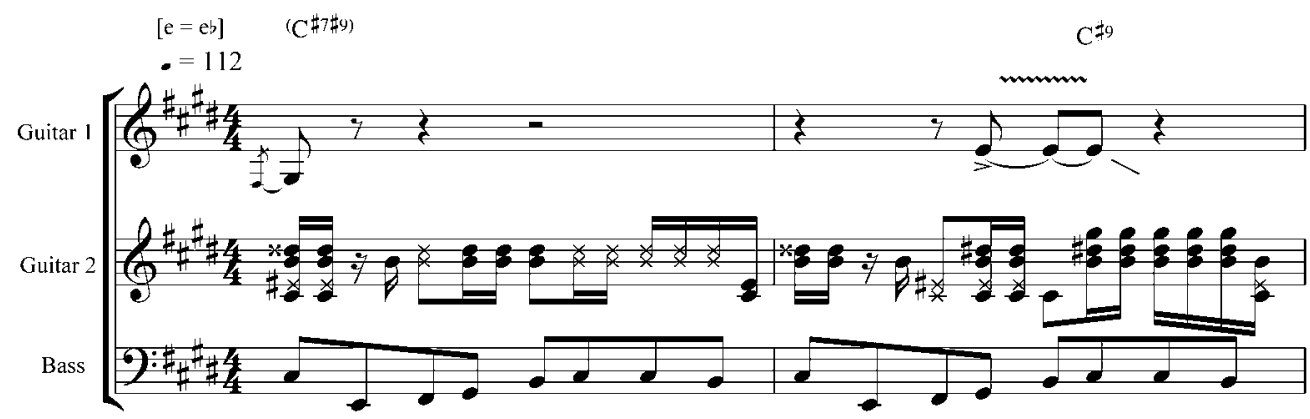

Example 25. 'Freedom' (1970) [0:18 FRNRS 26:I:2].

'Dolly Dagger' also builds on a chordal vamp, this time based on various inversions of B9, with no allusions to the sharp ninth sound. This is consistent until midway through the outro, where background vocals using the minor third and a typical sharp ninth voicing (with the major third omitted) mark the beginning of a 30-second fade-out (see Example 26). In terms of dynamics and timbre, this particular voicing is faint and distant in comparison to the hard-edged and distorted voicings of 'Foxey Lady' and 'Little Miss Lover'.

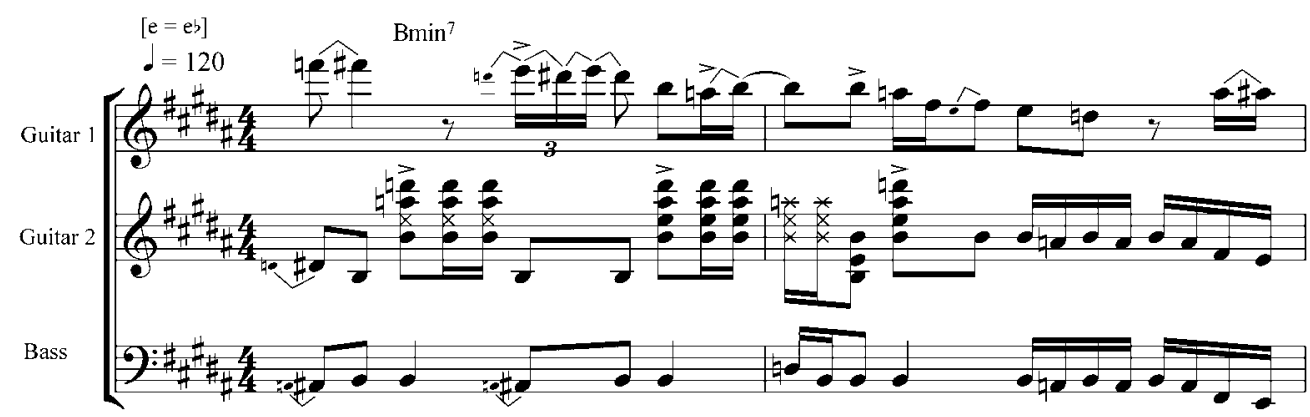

Example 26. 'Dolly Dagger' (1970) [3:55 FRNRS 123:I:1].

As Hendrix became more adept at using the studio as a tool to compose and arrange, he began to create increasingly dense textures through multi-tracking and timbrally manipulating his guitar parts. 'Ezy Ryder' is a prime example of Hendrix's skill in building up layers and then mixing and equalising them into a harmonically diffuse but timbrally united texture (see Example 27). This brief and pivotal 
appearance of the sharp ninth sound occurs in the middle of the bridge, halfway through the piece, emphasised through a different rhythmic groove. But compared to the rendition in 'Foxey Lady', which uses an identical registral leap between the root and the b7-b3 dyad, a subdued and blended effect minimises its aural impact.

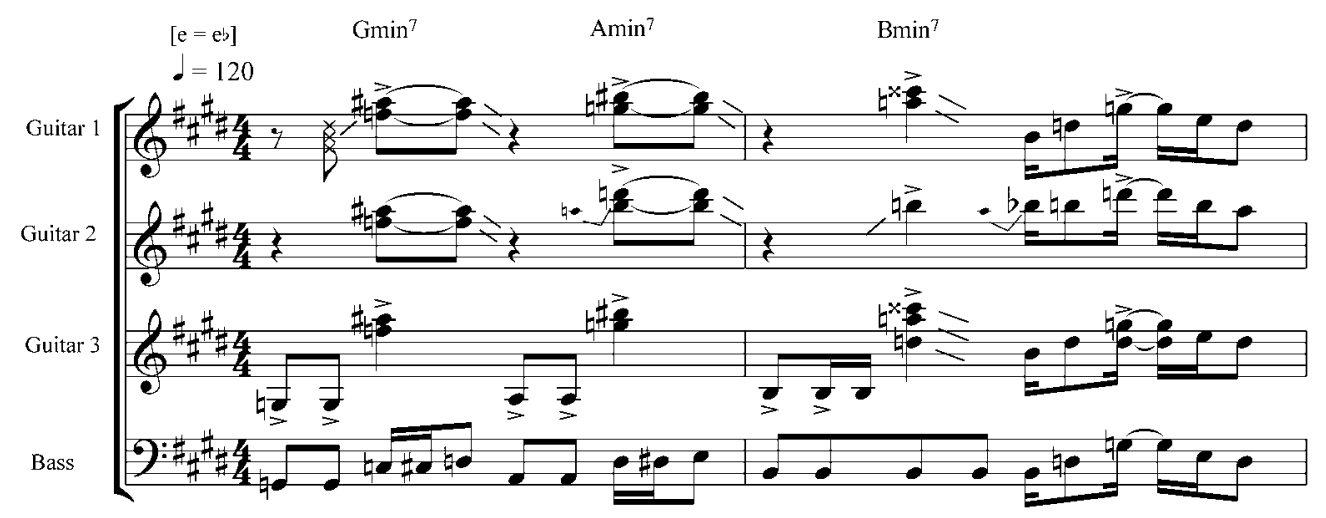

Example 27. 'Ezy Ryder' (1970) [1:47 FRNRS 132:II:2].

\section{Conclusion}

Hendrix was obviously very fond of the sharp ninth sound and used it to imbue his music with a blues feeling at strategic points in many of his compositions. His frequent use of the chord as tonic harmony reinforces this notion, since the chord can be heard as a coalescence of a significant portion of the characteristic pitch configuration used in the blues idiom. The notion of self-standing harmony placed in a harmonically open and ambiguous terrain helps us understand some of the more ornamental or incidental instances of the chord as found in Hendrix's music, and in particular, the juxtaposition of dissimilar chord qualities. Self-standing harmony allows for a flexibility in chord construction and sequences that transcends conventional notions of dissonance and its resolution. In some instances, the sharp ninth sound determines the overall character of the piece, while in others it acts more as a demarcation point or area of contrast. In instances where voicings are incomplete, in which a chord or chord fragment could be interpreted as being part of minor harmony since the major third is often missing, the complete voicing usually appears at another point in the piece, confirming the manifestation of an essentially ambiguous minor-major harmonic system. Register, articulation, dynamics and timbre all play a role in creating associations between different instances so that actual pitch content is sometimes less important in establishing associations. These components also play a role in differentiating between synchronous guitar parts, in some instances highlighting the sharp ninth sound and in others burying it in a dense, timbrally and dynamically variegated texture. Flexible pitch relationships, in part stemming from the blues idiom and in part from Hendrix's personal style, establish a rich, unpredictable (at least at the level of individual note articulation), loose and open environment.

There are essentially two approaches Hendrix uses in constructing the sharp ninth sound: (i) as a fully voiced mid-register chord, most instances of which stem from a single fingerboard shape (e.g. 'Purple Haze'), and (ii) as an incompletely voiced high-register distillation, usually containing the $b 7$ and $\$ 9$ (e.g. 'Foxey Lady'). 
It may be useful to think of the sound as a kind of signature, as his use of the wah-wah pedal, extended trills, and strings of broken chord dyads were. The post-performance aural highlighting of the sharp ninth sound in 'Voodoo Child' through echo and stereo panning certainly supports this notion. Or in a grander and more speculative vein, it can be interpreted as a musical grounding, an affiliation with blues performance practice that, regardless of how remote the harmonies are from traditional blues harmonic practices, still retains a deep connection to the blues idiom.

This helps explain some of the juxtapositions with ninth chords, and in fact, in one of his final studio efforts, 'Beginnings', Hendrix uses the sharp ninth sound as a means to bring a harmonically and rhythmically meandering piece to a conclusion. As with 'Freedom', an arpeggiated and fully voiced flat seventh sharp ninth chord marks the end (see Example 28). Without wanting to read too much into this event, it is tempting to conclude that Hendrix, somewhat adrift in his chordal explorations and seeking a kind of resolution, was reaching back to his rhythm-and-blues roots, a tradition in which the chord was often used in stop-time passages and endings, acting as a kind of musical punctuation. And considering that 'Beginnings' was one of his last studio compositions, recorded a mere month before he died in September 1970, it is symbolic of the path that he had taken and some of the territories he had yet to fully explore.

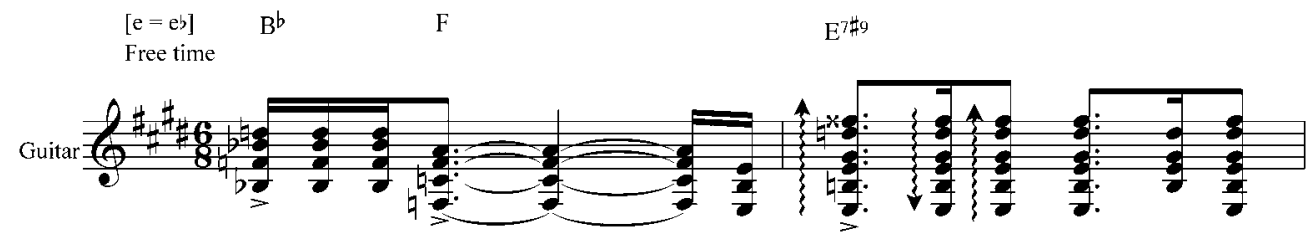

Example 28. 'Beginnings' (1970) [3:52 FRNRS 163:IV:1].

\section{Endnotes}

1. My thanks go to Stephen Blum, James Robbins, Robert Witmer, and the anonymous reviewers whose constructive suggestions have helped this paper evolve into a coherent whole.

2. There are many ways of describing this chord quality, including a major-minor seventh chord, major triad with a minor seventh, or the more limiting dominant seventh chord, but for expediency the term 'seventh chord' will suffice.

3. Of the numerous references to the chord on the Internet in various how-to pages and newsgroup discussions, the best example can be found in Guitar Axis Quick Tips of the Create section of the Experience Music Project website (www.emplive.com), where guitarist Don Mock devotes two video lessons to exploring the 'Hendrix Chord'.

4. This study focuses on Hendrix's performances on the studio albums, Are You Experienced, Axis: Bold as Love, Electric Ladyland and First Rays of the New Rising Sun [Cry of Love].

5. It could be argued that in the context of blues music the sharp ninth is mislabelled, since it really is heard as a flat 10th or flat $3^{\text {rd }}$, but the interval is nevertheless commonly referred to as a sharp ninth, regardless of context. Alternatives in notating the chord abound, especially in Hendrix's music, where key signatures seldom fit the music.

6. A good summary of how various writers have described blue notes can be found in Tallmadge (1984). He also offers the term 'blue tonality' to describe the simultaneous hearing of blue notes and underlying harmony: 'blue notes exist only in conjunction with a harmonic substructure, and the total sonority (blue tonality) is created by means of an Afro-American polychordal practice initiated in North America' (ibid., p. 163). Gerhard Kubik echoes this notion: '. . . one can first proceed from the simple, but cognitively relevant, axiom that intraculturally (i.e. for the performers themselves) the blue notes have no reality as separate conceptual pitch units. This is supported by the fact that Deep South blues singers themselves never talk about "blue notes" unless they have had some exposure to the jazz literature, have had Western formal musical training, or are influenced by fans from 
outside their primary community and audiences.... Their [blue notes'] existence as differential cognitional units is only generated through comparison with an extrasystemic parameter: the European diatonic scale' (Kubik 1999, p. 123). Finally, as David Evans puts it: '. . blue notes can be far more than neutral pitches. In fact, a variety of pitches within a single neutral range might be used in a song, suggesting aural shadings. A blue note might be expressed as a slur, usually upward from the flat toward the natural, or as a wavering between flat and natural or two other points within the interval. It might also occur as the simultaneous sounding of the flat and natural pitches or simply their use at different times in a piece, suggesting tonal ambivalence or compromise. Finally, it might simply be expressed by the sounding of a flat where a natural would be expected' (Evans 2001, p. 642).

7. It is worth mentioning that even though the twelve-bar blues is by far the most common form used in blues traditions, there are several other common forms, including eight-bar and sixteen-bar blues with varying harmonic schemes and phrase structures. Dauer (1979) provides a useful typology of these forms, extrapolated from a sample of 131 recordings drawn from a variety of historical periods and styles. And, in fact, Hendrix's concept of a blues, like most blues players, had more to do with a characteristic groove than an actual harmonic scheme, as can be witnessed in, for example, 'Hear My Train a Comin', 'Voodoo Chile', and 'Belly Button Window', all of which would immediately be recognised as blues compositions but none of which follow the standard twelvebar pattern. Hendrix's staple twelve-bar blues is 'Red House', which he included in the vast majority of his concerts during the three years that he toured with the Experience. During this period it evolved from a four-minute medium tempo blues with one solo chorus into an extended (up to fifteen minutes) slow blues with several timbrally and dynamically contrasting sections.

8. Titon 1994[1977], p. 154. In explaining the use of the scale, Titon resorts to using the term 'mode', which proves more useful: 'The most important pitches in the mode are the keynote $C$ and its octave $C^{\prime}$, the group of pitches in the E complex, the group of pitches in the $E^{\prime}$ complex, and G. Slightly less important are A, F, the G complex and the $\mathrm{B} b$ complex. Least important, but significant nonetheless, are D and its octave $\mathrm{D}^{\prime}$. I determined this hierarchical arrangement from the pitches' weighted frequency of appearance, their typical positions in melodic phrases, and their typical uses'. Titon's reasoning for counting discrete pitches instead of 'slurs' is that he hears them more as 'a variable sequence of pitch gradations which corresponded individually to each newly sung syllable, with slurs between the gradations. Rather than use the term blue notes, I prefer to point to complexes - pitch sequences around the third, fifth, seventh and tenth of the downhome blues mode - and to say that the complexes are used in specific but characteristically idiosyncratic ways' (ibid., p. 297).

9. Hanford similarly recognises a correspondence between vocal blues tradition practice (in which minor thirds in the melody line sit over major thirds in the accompaniment) and the Hendrix chord by suggesting that the chord may have 'originated in a verticalisation of the aforementioned melodic tones [the so-called blue notes] combined with either a conventional major triad or a seventh chord' (Hanford 2003, p. 104). I would argue for a connection that is incidental rather than causal, since the chord obviously existed and was used long before blues practice came into being.

10. Musical examples are referenced in two ways: (i) track time (ii) score location. For example, in 'May This Be Love', the reference [2:04 AYE 186:I:1] means that the example occurs 2 minutes and 4 seconds into the track and that it can be located on page 186, first system, bar 1 of the Are You Experienced (Transcribed Scores) transcriptions. For the other scores: ABL is Axis: Bold as Love (Transcribed Scores); ELL is Electric LadyLand (Transcribed Scores); and FRNRS is First Rays of the New Rising Sun (Guitar Recorded Versions). In some cases, I have changed or added chord symbols and transposed keyboard parts to match the key (the published transcriptions are prescriptive, with instructions for tuning guitar and bass down a semitone). Key signatures remain the biggest problem, however, since most of the music simply does not notate very well with conventional keys, but I have left them intact so that the excerpt can be viewed in the context of the rest of the score. Enharmonic spellings, inconsistently applied in the published transcriptions, have in some cases been simplified. For the transcriptions from FRNRS I have transcribed the bass line, since no full score has been published. In many instances, guitar and bass are tuned down by a semi-tone, or, in the case of 'Voodoo Chile', a tone; this has been indicated above the tempo marking. (Tuning the guitar down to Eb from E was a common trick used by rhythm and blues players who played with horn sections. It enabled them to play in native guitar keys, with their richness in harmonics and easier fingering, yet sound as if they were playing in native horn keys. But there were also many blues players, notably Albert King, whom Hendrix much admired, who regularly tuned their guitars down a half step.) As is customary with notated guitar and bass music, pitches sound an octave lower than notated.

11. Exceptions to this style of singing are tunes where Hendrix has crafted a chord progression with an accompanying melody that calls for a 'straight' interpretation, often in ballads such as 'Drifting' or 'Angel'. Hendrix was never very comfortable with his singing voice as he did not have a broad vocal range, but he did have a 
relaxed and inventive style of phrasing, an excellent sense of time, and a thorough command of the blues idiom.

12. Interestingly, Hendrix was very much aware of principles of structured and goal-oriented voice-leading, as Matthew Brown has demonstrated in his analysis of 'Little Wing', Hendrix's most well-known, most often covered composition (Brown 1997).

13. In Origins of the Popular Style, Peter van der Merwe discusses the relationship of melody and harmony in blues music. He convincingly argues that a gradual estrangement of melody and harmony, an 'uncoupling of the harness that held the two together in the European classical tradition', facilitated by the intrusion of late nineteenth century parlour music modes, enabled an independence of melody over harmony (van der Merwe 1989, p. 266). In the case of blues music, van der Merwe's argument rests on the supposition that melodic behaviour is governed more by the blues mode or the 'ladder of thirds', than by harmony (ibid., p. 125).

14. 'Hold it' was recorded in June 1958 and released on the King record label. Tracing the history of how and when the 'Hold It' chord became part of the vernacular is beyond the scope of this paper. Hanford describes how it was popularised by James Brown as a segue or break tune and mentions how musicians consequently began associating the chord with

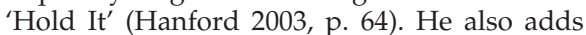
that 'In the arrangements of many 1960s rhythm and blues recordings, the augmented ninth chord often occurs as a "punch", a strong, typically syncopated accent, or as a "tag" or dramatic closing gesture ... In either context, when it is used as a punch or a tag, one of the most dissonant and complex chords in the rhythm and blues stylistic lexicon functions as a harmonic intensifier at local levels'. (ibid., p. 65). Internet newsgroups offer some evidence of its use, but mostly in the context of the folklore of the 'Hendrix chord'. One firsthand account can be found in an interview with jazz guitarist John Scofield, as described in Keith Shadwick's Jimi Hendrix: Musician (Shadwick 2003): 'When I first started to play guitar - this was before Hendrix - there was a chord known as the 'Hold It' chord, an E sharp 9. It was based on a break tune that came from an older generation, a Bill Doggett song from the '50s. And then Hendrix started to play this chord and it became known as the Jimi Hendrix Chord' (Milkowski 2001, p. 45).

15. I have notated the sharp ninth as $\mathrm{Eb}$ in the transcription mainly for ease since it becomes the $b 7$ of F7.

16. Chuck Berry's 'Beautiful Delilah' was recorded in May 1958 and was originally released as a Chess single. The Kinks included their version on their first LP, recorded in 1964 and originally released on Pye Records. Noteworthy is that the Kinks' rendition truly capitalises on the distinctive bite that the sharp ninth chord produces by having it featured prominently in the mix. The Beatles' 'The Word' was recorded in November 1965 and released on the Parlophone album Rubber Soul.

17. 'Testify, Parts 1 and 2' was recorded March 1964 by the Isley Brothers and released later that year as a 45 RPM single on the T-Neck label. The transcription is an approximation of what Hendrix and the bassist are playing since it is very difficult to separate out the parts from a very dense and distorted sound that includes shouting vocals, horns, organ and drums, all of which are buried in a monophonic mix.

18. 'Last Night' and 'Shotgun' are available on The Complete PPX Recordings (SPV Recordings: SPV 088-29802), a six-disc set released in 2000. 'Under the Table' is available on Jimi Hendrix: The Early Years (Charley Records CDCD 1189), released in 1994.

19. Rock guitarists often omit the third in barre chords, emphasising the octaves and fifths to create a typical 'power chord' sound. In 'Purple Haze' Hendrix actually articulates the thirds of both $\mathrm{G}$ and A chord, albeit with less emphasis than the octave and fifth.

20. Everett 2004 (pp. 19-20) discusses this as being a type of harmonic progression particular to rock music, framing it within the context of pentatonicism rather than mixed modality.

21. Hanford characterises this figure as being related to what he has termed the "II Don't Live Today" Riff and Lick' (Hanford 2003, p. 67). There is no doubt that 'Ain't No Telling' and 'I Don't Live Today' are distinguished by their use of a bend into the fifth, and by emphasising this connection it is possible to relate it to a larger pool of figures based on the bending of a fourth into a fifth. We can hear the result as being simultaneously part of two of Hendrix's signature sounds.

22. The range of variables and their interaction that contributed to Hendrix's sound is the topic of another paper. As a left-handed guitarist, Hendrix used off-the-shelf right-handed Fender Stratocasters, with a result that the reverse staggered pickups inadvertently emphasised different harmonics than they were set up to do. $\mathrm{He}$ also often tuned a semitone below normal tuning, producing a different timbre and more opportunities for string bending. Hendrix's effects pedals included the wah-wah, Univibe, Fuzz Face, and Octavia. The wah-wah pedal essentially is a foot-controlled bandpass filter with a moveable resonant peak that allows you to move incrementally from one timbre to another. Initially Hendrix just moved the pedal up and down along with the beat but as he became more adept at it he began to shape his melodic lines and rhythm guitar parts with the device, often emulating speech patterns. This was possible since the wah-wah pedal produces harmonic partials that are very similar to the formants found in vocal sounds. The Fuzz Face produced a square waveform in emulation of speaker distortion. Less-used effects included 
the Univibe and the Octavia. The Univibe simulated the rotating speaker of a traditional Leslie organ cabinet and was capable of producing both chorus and vibrato effects. The Octavia was essentially a frequency doubler, but because it would double partials as well as fundamentals, it produced a much richer and unpredictable sound than simply playing octaves.

23. In live versions, Hendrix was not always successful in producing the $a$, leading to different harmonic scenarios.

24. The guitar part is doubled by piano (not included in the transcription), although because of equalisation, mixing, and a continuously depressed damper pedal it is difficult to accurately hear the points of attack.

25. Interestingly, Aledort has labelled the guitar/ bass lines and chord fragments in parentheses as $C \sharp 7 \sharp 9$ throughout, thereby acknowledging the implied presence of the sharp ninth sound.

26. 'Chugs' is a descriptive term coined by Andy Aledort, referring to 'muted strings attacked in sharp, staccato fashion with the picking hand' (Aledort 1995, p. 66). Hendrix was a master at incorporating this technique into his lead and rhythm guitar work and he often combined it with the wah-wah pedal to produce a unique rhythmic sound. The most well-known example is the opening to 'Voodoo Chile (Slight Return)'.

27. Aledort notates the $g$ in the guitar part as $f$-double sharp, but given the fact that the key signature indicates E Aeolian, it makes more sense to use $g$-natural.

28. The full voicing does occur briefly in the second verse in the rhythm guitar part.

29. The term 'outro' has been adapted from the transcriptions, where it indicates an extended ending, often leading to a slow fade-out.

30. An important development during Hendrix's last year was his temporary musical collaboration with soul artist and drummer Buddy Miles and the more permanent relationship with his long-time friend and bassist Billy Cox. This collaboration resulted in the much-touted Fillmore East concerts on 31 December 1969 and 1 January 1970. The music was decidedly different, relying on riff-based extended improvisations with little harmonic movement over a soul-based rhythmic foundation. See Hanford (2003) for a thorough account of this music.

\section{References}

Brown, Matthew. 1997. 'Little Wing: A Study in Musical Cognition', in Understanding Rock: Essays in Musical Analysis (New York: Oxford), pp. 155-169

Dauer, Alphons. 1979. 'Towards a Typology of the Vocal Blues Idiom', Jazzforschung 11, pp. 9-92

Evans, David. 2001. 'Blues', in The Garland Encyclopedia of World Music, Vol. 3: The United States and Canada (New York: Garland), pp. 637-649

Everett, Walter. 2004. 'Making Sense of Rock's Tonal Systems', Music Theory Online 10/4 [http:// www.societymusictheory.org; accessed March 26, 2005]

Forte, Allen. 1995. The American Popular Ballad of the Golden Era, 1924-1950 (Princeton)

Hanford, John. 2003. 'With the Power of Soul: Jimi Hendrix in Band of Gypsys', Ph.D. dissertation, University of Washington

Kubik, Gerhard. 1999. Africa and the Blues (University Press of Mississippi)

Milkowski, Bill. 2001 'Modern jazz axis: Bold as Jimi', JazzTimes, 31/6 (July/August 2001), pp. 42-55, 156

Shadwick, Keith. 2003 Jimi Hendrix: Musician (San Francisco: Backbeat Books)

Tallmadge, William. 1984. 'Blue notes and blue tonality', The Black Perspective in Music, 12/2, pp. 155-165

Titon, Jeff Todd. 1994 [1977]. Early Downhome Blues: A Musical and Cultural Analysis, second edition (Chapel Hill: University of North Carolina)

Van der Merwe, Peter. 1989. Origins of the Popular Style: The Antecedents of Twentieth-Century Music (Oxford) Weisethaunet, Hans. 2001. 'Is there such a thing as the "blue note"?', Popular Music 20/1, pp. 99-116

\section{Scores}

Aledort, Andy. 1995. In Deep with Jimi Hendrix (Experience Hendrix, distributed by Hal Leonard) 1996. Are You Experienced (Transcribed Scores) (Experience Hendrix, distributed by Hal Leonard) 1996. Axis: Bold as Love (Transcribed Scores) (Experience Hendrix, distributed by Hal Leonard) 1996. Electric Ladyland (Transcribed Scores) (Experience Hendrix, distributed by Hal Leonard) 1997. First Rays of the New Rising Sun (Guitar Recorded Versions) (Experience Hendrix, distributed by Hal Leonard)

\section{Discography}

Hendrix, Jimi. Are You Experienced. Experience Hendrix MCASD-11602. 1997[1967]

Axis: Bold as Love. Experience Hendrix MCASD-11601. 1997[1967]

Electric Ladyland. Experience Hendrix MCASD-11600. 1997[1968]

First Rays of the New Rising Sun. Experience Hendrix MCASD-11599. 1997[1968] 